\title{
Bridging the gap between academic and policy-oriented activities in higher education institutions
}

\section{Laura Márquez-Ramos}

Department of Economics, Universitat Jaume I, Castellón de la Plana, Spain, University of Adelaide, Adelaide, Australia.

\begin{abstract}
There are three different types of activities performed in higher education institutions that, taken together, form the components of a trilemma in higher education. These include traditional academic activities (research and teaching), along with those that aim to transfer knowledge beyond academic research (policy-/industry-oriented activities). I argue that there are potential synergies across these three components that can be exploited to resolve this trilemma. This is illustrated in an augmented research value chain that introduces teaching and policy-/industry-oriented activities as phases that complement the research process. The interaction of the different phases in the research process contributes to the generation of new knowledge, increasing the value-added of the organization. This proposal relies on an application in an organizational unit specializing in international trade within an Australian university. Australia provides an interesting case study because researchintensive Australian universities are no longer evaluated purely in terms of their research quality, but also in terms of their transfer of knowledge and contributions beyond academic research. In this context, I conceptualize how to resolve the trilemma, and increase the feasibility of bridging the gap between academic and policy-/industry-oriented activities in higher education institutions.
\end{abstract}

Keywords: higher education; policy-/industry-oriented activities; teaching; research; trilemma; research value chain. 


\section{Introduction}

Recent reforms in higher education have led to the emergence of what are known as managerial universities, which focus on effectiveness and efficiency and give rise to important changes in related organizational structures (Hagerer 2019). In this context, universities' success in rankings becomes more important, but at the same time, they must be able to attract funding. A key trade-off is how to secure more funding, which normally arises from applied, professional, and policy-/industry-oriented projects, while ensuring the necessary level in research quality that allows universities to maintain their reputation and prestige in national and international rankings. At the same time, teaching is a key university function and constitutes a source of revenue. The main objective of this paper is to evaluate the feasibility of bridging the gap between academic and policy-/industry-oriented (hereafter referred to as policy-oriented) activities in higher education. I argue that these three types of university activities, taken together, are the three components of a (policy-research-teaching) trilemma in higher education; however, there are synergies across the different activities performed in universities that can be exploited to resolve this trilemma. This is illustrated in an augmented research value chain that introduces policy-oriented and teaching activities as important phases in the research process that add value to the organization (by generating new knowledge).

This paper highlights a long-running problem on the difficulty of balancing teaching, research, and policy-/industry-oriented activities. Previous research highlighted how the different agendas of the research community and practitioners generate a communication gap between research and policy-oriented activities, and pointed out the need for informed entrepreneurs in universities that both understand and appreciate research and can package it so that it can be used by practitioners (Hallinan 1996). Dunne and Rawlins (2000) claimed the existence of a gap between industry and higher education and underlined the need for a dual approach: top-down alongside bottom-up change in higher education institutions. More recently, Roudaut (2019) aimed to bridge the gap between teaching and research, recognizing that research-led teaching is challenging because of the difficulty of conveying to the students the uncertainty of scientific outcomes. The idea of bringing research into teaching is not new and researchers have already drawn attention to the benefits of such a practice. However, Marsh and Hattie (2002) tested the teaching-research hypothesis - namely, that there is a positive relation between the two types of activities - and found a near-zero correlation. According to their results, good researchers are neither more nor less likely to be effective lecturers than are poor researchers, and good lecturers are neither more nor less likely to be productive researchers than are good lecturers. This is consistent with Norton and Cherastidtham (2015), who highlighted that positive and negative theories explaining the teaching-research relationship could cancel each other out. 
Regarding the relationship between academic and policy-/industry-oriented university activities, there is a growing number of initiatives aiming at increasing the science-industry knowledge exchange. Formal channels of interaction include collaborative and contract research, academic consultancy, intellectual property transactions, labor mobility, and academic spin-offs. Informal channels include conferencing and networking, facility sharing, and continuing education provided by universities to enterprises (Guimón and Paunov 2019; Paunov et al. 2019). The dynamics and complexity of collaborative research linkages between university and industry were analyzed by, e.g., Plewa et al. (2013). These authors stated that university researchers actively engage in research with commercialization potential and industry increasingly recognizes the value that university knowledge can add to commercial research and development. Other models of linkages are also possible, e.g., independent think-tanks that act as intermediaries between academic research and policy discussion.

To the best of my knowledge, the existing literature generally emphasizes the importance of a series of "dilemmas", while I conceptualize a trilemma. Indeed, previous studies are silent about the policy-research-teaching relationship. By relying on an application in an Australian university, I take a step in this direction and I repackage the difficulty of balancing teaching, research, and policy-/industry-oriented activities, which yields new perspectives and insights.

In Section 2, this paper briefly describes the evolution of the research function in universities and defines key concepts to contextualize the research function in the Australian higher education system. Section 3 formalizes a trilemma that includes the three types of university activities or components analyzed, and illustrates the interactions and potential synergies existing between its components. Section 4 presents a (traditional) research value chain, which is then modified to fit the reality Australian universities currently face. The potential synergies between research and other university activities are illustrated in an augmented research value chain that is helpful in identifying feasible ways to resolve the policy-researchteaching trilemma. Section 5 concludes.

\section{The research context in the Australian higher education system}

In the history of higher education in the US, Ford (2017) distinguished four phases that are characterized by their primary function: preserving Christian civilization, advancing the national interest, research, and growing the global economy. It was in the $19^{\text {th }}$ century when a group of German philosophers and bureaucrats succeeded in establishing the world's first research university, the University of Berlin, which would go on to shape how we understand the functions of higher education. Its main objective was to conduct research, and the vision of the importance of academic research in German research-intensive universities has since been incorporated into public education worldwide. The research university places a greater 
value on research than on teaching and while professors at a research university typically have some teaching responsibilities, this is not their primary activity (see Ford 2017). The shift in the US higher education system is a good illustration: leading US research universities added to the innovation by changing the nature of $\mathrm{PhD}$ training, paying less attention to undergraduate teaching; specialized high-fee colleges offering the best undergraduate teaching; and community colleges providing pathways for poorer students. Márquez-Ramos and Mourelle (2016, 2018), on the basis of potential responses to the societal trends of the knowledge economy (Castells 1996), recognized that the functions of higher education are shifting and the future of higher education is not entirely foreseeable. In a changing environment, Australia provides an interesting case study of how future directions and uses of higher education might be transformed (Nunan 2005) as Australian research-intensive universities are no longer evaluated purely in terms of their research quality, but also in terms of their transfer of knowledge and contributions beyond academic research. Interestingly, in a comparative study between two developed countries with similar levels of per capita expenditure on their higher education research and development, Australia and Germany, Plewa et al. (2013) state that "their funding systems differ: Germany offers strong core funding for universities, coupled with relatively low external funding opportunities, whereas in Australia, a highly competitive performance-driven funding model dominates" (page 25).

Nowadays, Australian universities are subject to an evaluation exercise at national level, in addition to the evaluation of their research quality in every field of research (the so-called ERA: Excellence in Research for Australia). Running alongside the ERA assessment, the Engagement and Impact (EI) assessment examines how universities are translating their research into economic, social and other benefits (see Appendix A for definitions in Australia). Both research and teaching are core functions in Australian universities. Regarding teaching, the difference between teaching revenue and costs (a teaching surplus) provides funds that can be used to pursue objectives that are not financially self-sustaining (e.g., research). Interestingly, research is supported by large surpluses from university teaching in Australia: one dollar in five spent on research comes from surpluses on teaching (this is based on conservative assumptions, see Norton and Cherastidtham 2015).

\section{The policy-research-teaching trilemma}

I analyze the relationship between policy-/industry-oriented and research activities together with the teaching-research relationship. I name these three key university components as follows: I) "policy", including a policy-/industry- and a consulting aspect; II) "research"; and III) "teaching", which also includes types of alternative teaching apart from teaching in university degree programs, such as capacity-building programs. Figure 1 illustrates the three different types of university activities (or components) considered in this research. It is worth considering that balancing the different policy-research-teaching activities in a university 
context is challenging. The academic staff is under pressure to publish their research in esteemed publications, while still performing their teaching activities. Higher pressure on academic staff might reduce their incentives to invest their time in improving their teaching, as they seek to focus on their research outcomes. This, together with the fact that many universities are increasing their involvement in engagement and impact activities (e.g., transmitting new knowledge to research end-users beyond academia, catalyzing societal change, and creating direct benefits for the wider community) and pressure to secure more funding from applied, professional, and policy-/industry-projects, creates a trilemma.

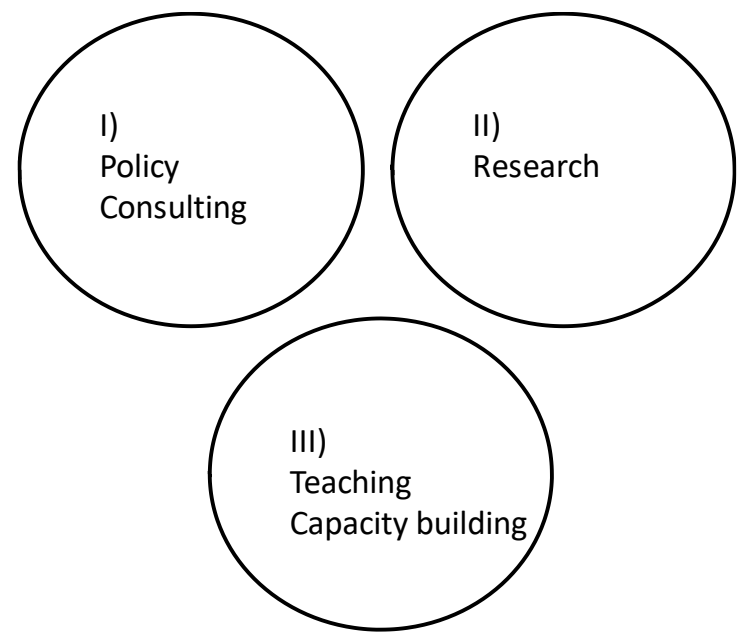

Figure 1. Three components in higher education institutions (policy-research-teaching).

In response to the existing challenges, Figure 2 presents the policy-research-teaching relationship in the form of a trilemma. According to this trilemma, engagement \& impact, research quality, and teaching quality (as represented in the corners of the inverted triangle in Figure 2) are all desirable but cannot be easily balanced. There are three possible responses that balance the demands of two of the three elements of the trilemma, but which then jeopardize the achievement of a more effective and efficient higher education organizational unit. The first is to opt for a mix that prioritizes traditional university activities, i.e., research and teaching, to achieve high research and teaching quality. This option would not enable an optimal response to the fact that Australian universities not only need to involve in engagement and impact activities, but also to generate additional income beyond teaching. This is especially relevant in the present context, as Australian universities will, very likely, decrease significantly their number of international students due to the Coronavirus crisis. The second possible response is to pursue a business model that centers on revenuegenerating activities (i.e., policy-oriented and teaching). However, to succeed at attracting students and funding from research end-users, a university not only requires high teaching 
quality, but also high research quality, which is key for maintaining a good position in national and international higher education rankings; in turn, these positions are heavily influenced by research outcomes and performance. And the third and last possibility is to set less ambitious targets regarding teaching quality, thus limiting the potential for developing a teaching reputation and community worldwide (e.g., through alumni networks), and missing an important source of income.

I argue that the three components (policy-research-teaching) taken together constitute a trilemma in the higher education system, that is, once considered that these components are interrelated; however, synergies among the three components can be exploited to resolve the trilemma. Synergies are represented in Figure 2 with the overlapping areas between two components, including a smaller area representing the overlap where all three components present synergies (compare Figure 2 to Figure 1). The larger the overlapping areas, the more synergies exist in a given university organizational unit.

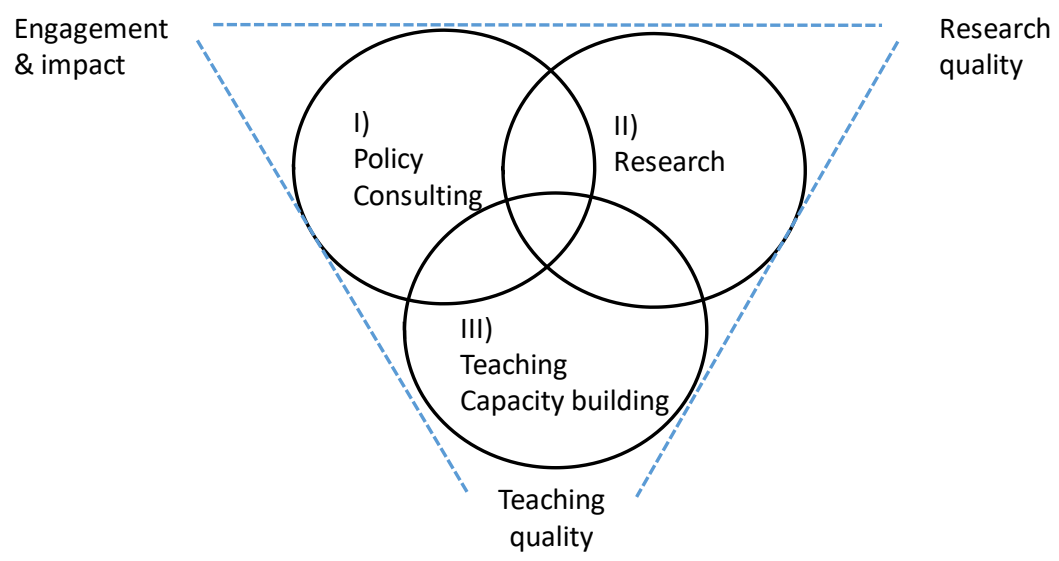

Figure 2. The policy-research-teaching trilemma in higher education institutions.

\section{An augmented research value chain to resolve the trilemma}

To provide a better understanding of how synergies arising from the different types of activities performed (or components of the trilemma) might be exploited to increase effectiveness and efficiency in university organizational structures, I start out from a research value chain that considers research to be the medium through which universities can transform inputs, i.e., labor (hours dedicated to research, number of researchers, etc.) and capital (laboratories, computers, technical equipment, etc.) into the generation of new knowledge. The blue arrow in Figure 3 represents the research process, while the grey area represents the value-added of research outputs to the organization. In addition, Figure 3 reflects the possibility that different university organizational units give different value to the 
generation of new knowledge. Specifically, in Figure 3, "unit B" represents a "traditional" university unit that is in line with the idea of prioritizing academic research and gives more value than "unit A" does to high quality research outcomes and to the generation of new knowledge (as represented by a larger grey area-i.e., higher value-added of the research outputs - in "unit B" than in "unit A").

This illustration does not account for the restrictions that universities face. In addition to other environmental changes faced by Australian universities, such as government underfunding, one has to consider how universities are evaluated. To this end, university managers in Australia take into account several indicators, such as research income, high-quality publications, and impact, i.e., societal change brought about by research output. I focus on a type-A higher education organizational unit to augment the research value chain because this paper has emphasized the interconnections and synergies between the three components in the (policy-research-teaching) trilemma.

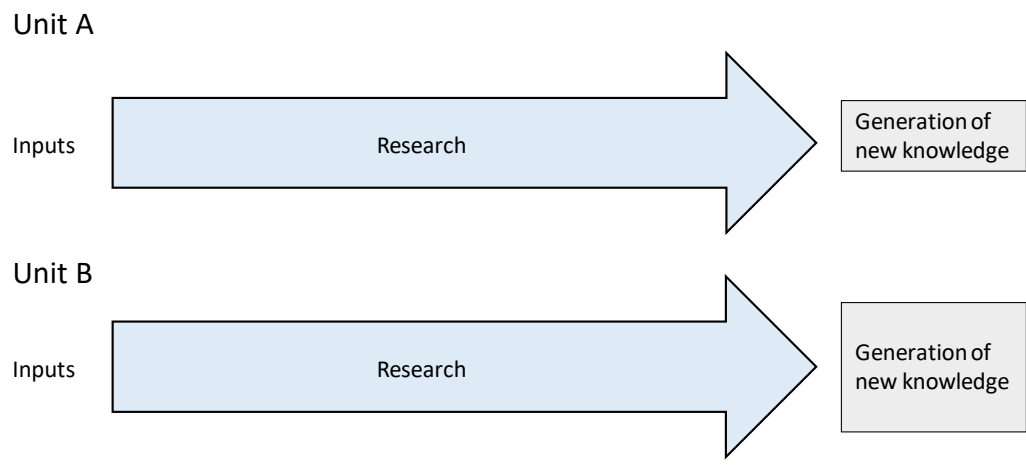

Figure 3. The research value chain.

I consider that the growing importance of university activities other than research constitute phases of the research value chain that might add value to the organization. Figure 4 shows that the components of "teaching" and "policy" can become complementary phases in the research value chain that enrich the research component by providing elements such as meaningful research questions that are relevant for policy makers or additional funding to hire new researchers, expanding the research community. By relying on experts' opinions in the field of international trade, the Appendix B provides two examples of complementarity in the augmented research value chain. 


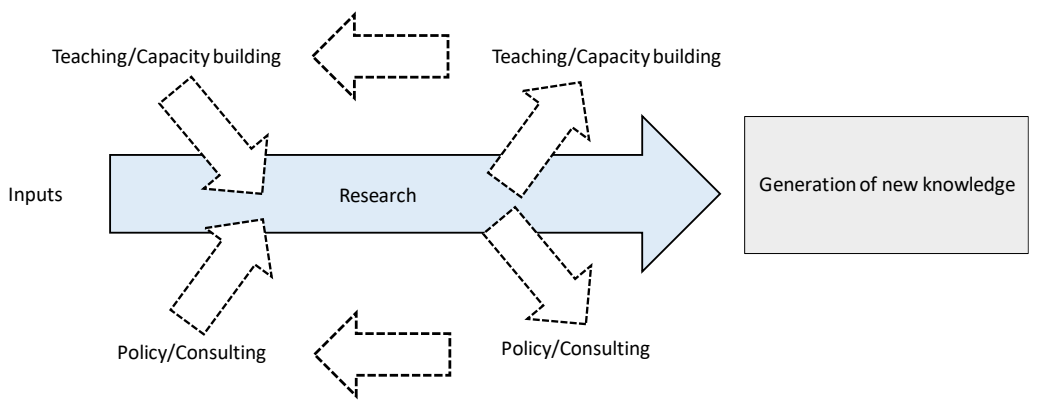

Figure 4. An augmented research value chain.

This evidence about complementarity between different phases of the research value chain relies on the field of international trade. Further analyses in alternative fields of research are needed so that they can be generalized to other areas. Further research might consider heterogeneity within and among the three components of the trilemma. For example, in Australia the government sees research as scientific research and there is a bias against humanities; the teaching-research relationship varies by higher education level, being very strong in $\mathrm{PhD}$ electives; and some research has immediate value, so it can be the basis of university-industry collaboration. Other research does not, however, it might be valuable for society or as basic knowledge on which more applied future research can be based.

\section{Conclusion}

This paper provides a new perspective and a meaningful starting point for the analysis of the policy-research-teaching relationship in higher education institutions. I have formalized a trilemma and I have illustrated the importance of potential synergies and the complementarity of research with other university activities (i.e., teaching and policy-/industry-oriented) in an augmented research value chain. This helps identify feasible ways to resolve the trilemma and to bridge the gap between academic and policy-oriented activities in higher education.

\section{Acknowledgements}

I developed the idea for the research value chain while in my role as Associate Head of Research of an institute in an Australian university. I am profoundly grateful for the feedback provided by the Executive Director of this institute, Peter Draper, by the leader of the University of Adelaide for the field of research "Economics" in the Excellence in Research for Australia (ERA) evaluation round 2018, Dr. Benedikt Heid, and by the Jean Monnet Chair in the Economics of European Integration of the University of Adelaide, Dr. Richard Pomfret. 


\section{References}

Castells, M. (1996). The Rise of the Network Society. Oxford: Blackwell Publishers.

Dunne, E., \& Rawlins, M. (2000). Bridging the gap between industry and higher education: Training academics to promote student teamwork. Innovations in Education and Teaching International, 37(4), 361-371.

Ford, M. (2017). The functions of higher education. American Journal of Economics and Sociology, 76(3), 559-578.

Guimón, J., \& Paunov, C. (2019). Science-industry knowledge exchange: A mapping of policy instruments and their interactions. OECD Science, Technology and Industry Policy Papers, (66), 1-33.

Hagerer, I. (2019). Universities act differently: identification of organizational effectiveness criteria for faculties. Tertiary Education and Management, 25(3), 273-287.

Hallinan, M. T. (1996). Bridging the gap between research and practice. Sociology of Education, 69, 131-134.

Márquez-Ramos, L., \& Mourelle, E. (2016). Selecting a suitable approach to analyze the future of higher education. Procedia - Social and Behavioral Sciences, 228, 86-91.

Márquez-Ramos, L., \& Mourelle, E. (2018). On the relationship between society and higher education: what path should we take? Distance Education, 39(1), 19-36.

Marsh, H. W., \& Hattie, J. (2002). The relation between research productivity and teaching effectiveness. The Journal of Higher Education, 73(5), 603-641.

Norton, A., \& Cherastidtham, I. (2015). The cash nexus: how teaching funds research in Australian universities. Grattan Institute.

Nunan, T. (2005). Markets, distance education, and Australian higher education. International Review of Research in Open and Distance Learning, 6(1), 1-11.

Paunov, C., Guimon, J., Borowiecki, M., \& Planes-Satorra, S. (2019). University-industry collaboration: New evidence and policy options. Highlights of the 2017-18 OECD Knowledge Transfer and Policies project.

Plewa, C., Korff, N., Johnson, C., MacPherson, G., Baaken, T., \& Rampersad, G. C. (2013). The evolution of university-industry linkages - A framework. Journal of Engineering and Technology Management, 30(1), 21-44.

Roudaut, A. (2019). Bridging the gap between teaching and research: a case study for engineering \& applied science. Higher Education Pedagogies, 4(1), 209-225.

\section{Appendix A. Definitions in Australia}

The Australian Research Council (ARC) defines research as "the creation of new knowledge and/or the use of existing knowledge in a new and creative way to generate new concepts, methodologies, inventions and understandings. This could include the synthesis and analysis of previous research to the extent that it is new and creative."

Research engagement is defined as "the interaction between researchers and research endusers outside of academia, for the mutually beneficial transfer of knowledge, technologies, 
methods or resources;" while research impact is the "contribution that research makes to the economy, society, environment or culture, beyond the contribution to academic research."1

\section{Appendix B. Two examples of complementarity in the augmented research value chain}

Example 1: Phase 1 (teaching) --> phase 2 (research) --> phase 3 (teaching and policyoriented activities) --> phase 4 (research). The organizational unit analyzed in this research provides education in international trade through capacity-building programs. On many occasions, these capacity-building programs have been delivered to policymakers and ministerial staff in developing countries. After completing these programs, some former students apply to become $\mathrm{PhD}$ students in the unit. If successful, these $\mathrm{PhD}$ students join a research group and collaborate with their research supervisors, bringing first-hand experience of policy-relevant research questions, which might lead to joint research papers with their supervisors. In addition, these $\mathrm{PhD}$ students might participate in the unit's teaching or capacity-building activities or collaborate with staff in policy- or industry-oriented projects, once they have achieved the necessary knowledge in the field. The teaching and policy/industry-oriented phases equip the $\mathrm{PhD}$ students with additional knowledge that complements their research. Moreover, through participation in collaborative networks that are pertinent to their research topics, they can benefit from further relevant feedback.

Example 2: Phase 1 (policy) <--> phase 2 (research). Staff of the unit might work on a policy project aimed at providing a solution for a government's specific problem. This project might provide funding for hiring a specialized researcher who will collaborate with institute staff. The institute staff involved and the specialized researcher can mutually benefit from the networking and collaboration. Institute staff might gain a more profound knowledge of stateof-the-art methods and techniques through the researcher, and the researcher might benefit from applying her knowledge to a policy-relevant problem. Further joint research might emerge, which yield research papers or collaboration in future projects.

\footnotetext{
1 See https://www.arc.gov.au/news-publications/media/presentations/standard-excellence-research-australia-era-and-engagementand-impact-ei-2018-outcomes
} 